\title{
VALIDATION OF LARGE EDDY SIMULATION OF THE HEAT TRANSFER INDUCED BY AN IMPINGING JET USING QUANTITATIVE INFRARED THERMOGRAPHY
}

\author{
Philippe Planquart ${ }^{1}$, Jean-Marie Buchlin ${ }^{2}$ \\ 1: Email: planq@,vki.ac.be, tel: 32-2-3599677, fax: 32-2-3599600 \\ 2: Email: buchlin@vki.ac.be, tel: 32-2-3599614, fax: 32-2-3599600 \\ von Karman Institute for Fluid Dynamics \\ EA department \\ Chaussée de Waterloo, 72 \\ B-1640 Rhode-St-Genèse \\ Belgium
}

Key words: validation, heat transfer, impinging jet, LES, infrared thermography

Impinging fluid jets are widely used in industrial processes where high momentum and/or mass transfer have to be reached. Typical applications are jet wiping, the drying of paper and textile, the cooling of turbine blades, the anti-icing of aircraft, the tempering of glass sheets, the cooling of moving metal strips, the cooling of electronic equipment, ...

Numerical simulations of these impinging jets are mainly performed solving the Reynolds Averaged Navier-Stokes equations. However, it has been shown that this approach for the simulation of turbulence overestimates the heat transfer coefficient at the impinging region (overestimates of 100\% have been observed). Therefore, the Large Eddy Simulation (LES) approach, which models only the small scales of turbulence and resolves the large scales is used to compute a round impinging jet with a Reynolds number varying from 3.000 to 70.000 .

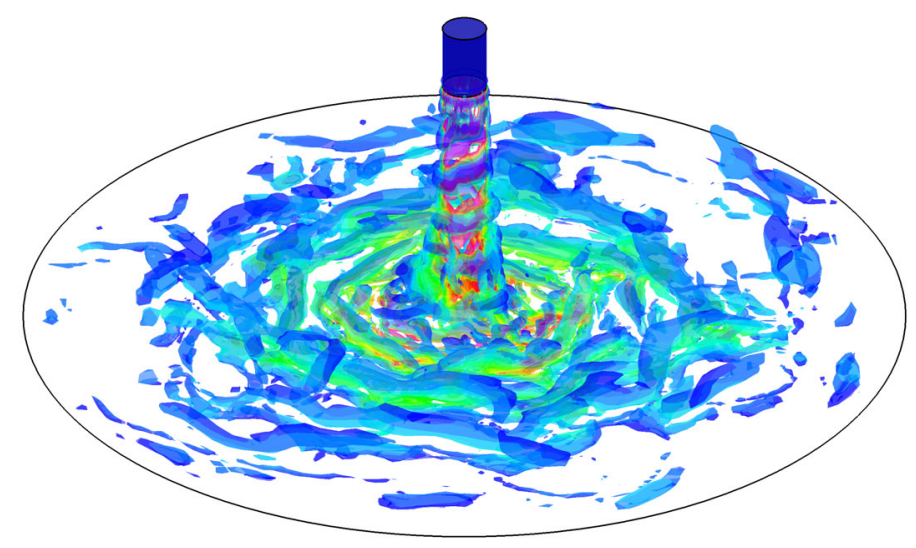

Figure 1 - Coherent structures in an impinging $S R N$ jet at $\operatorname{Reynolds}=70.000$ and $Z / d=7$

Large eddy simulation, by its unsteady nature, is able to capture coherent structure within the flow like the ones shown in the following figure. These structures as shown in figure 1 where a typical LES simulation is displayed, will influence the heat transfer coefficient at the impinging wall.

Experimental data needed for the validation of the Nusselt number are obtained by the infrared thermography. Heat transfer coefficients are deduced from the temperature mapping of a heated flat plate impacted by a $\underline{\text { Single }} \underline{\text { Round }} \underline{\mathbf{N}}$ ozzle air jet as sketched in figure 2 . The 
measurement are performed with a ThermaCAMTM SC3000 system. The normalised distance between the camera and the heated plate (Z/D) varies from 1 to 10 and the Reynolds number from 20000 to 70000 . A typical false-colour IR. thermogramme of the impingement region is shown in figure 3 , while subsequent radial distribution of the dimensionless convective heat transfer is plotted in figure 4.

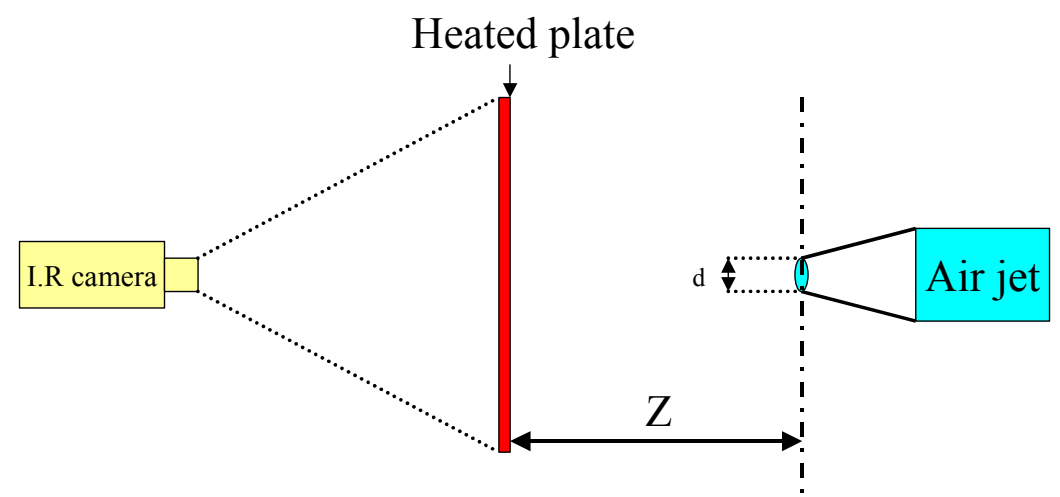

Figure 2 - schematic of ketch of the experimental facility

LES simulation and IR experimental results will be also compared to the data published by Baughn $(1989,1992)$. The industrial objective of this research is the study of thermal antiicing system designed for jet aircraft. The system uses jets of hot air impinging on the leading edge of the wings to perform the convective heat transfer. The numerical optimisation of these multijet anti-icing systems requires confidence in the turbulence modelling used in the numerical simulation. With this study, we will conclude on the use of Large Eddy Simulation for the turbulence modelling of heat transfer by an impinging round jet.

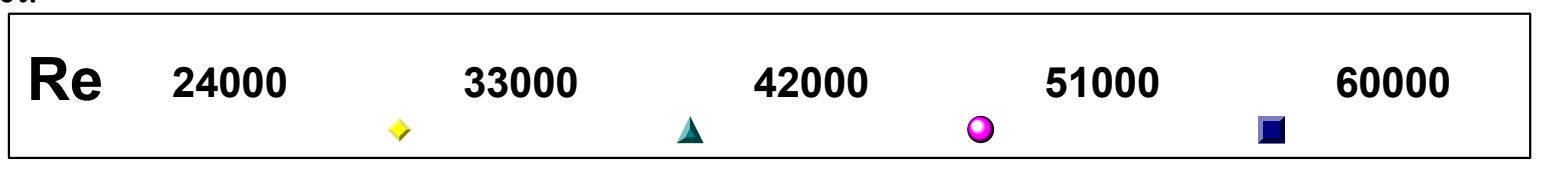

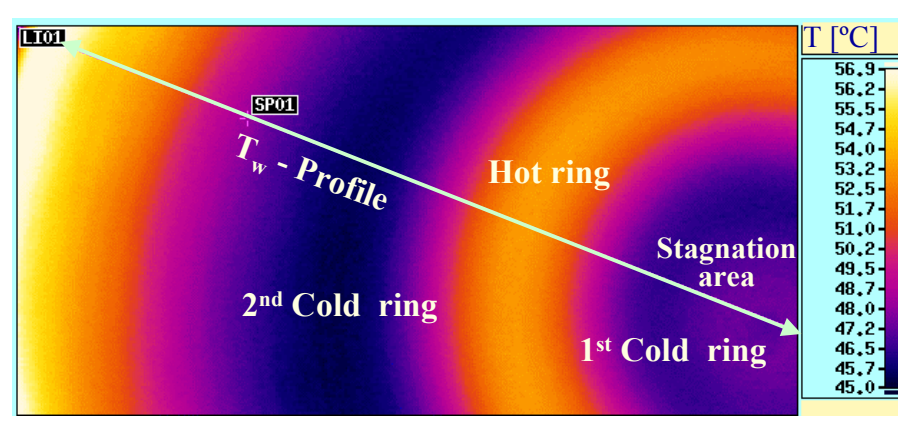

Figure 3: Thermogramme of the impingement

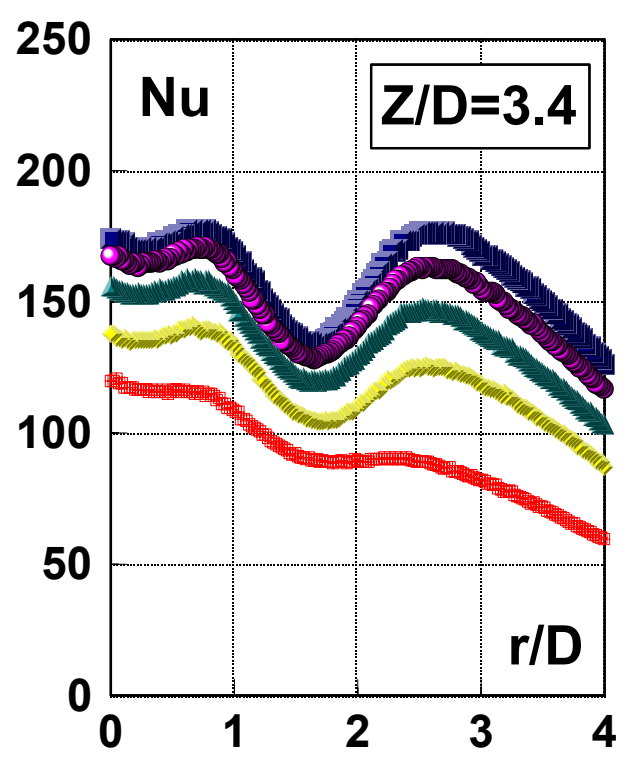

Figure 4: Radial $\mathrm{Nu}$-profile: effect of Reynolds number 